\title{
USING SIMULATION FOR LAUNCH TEAM TRAINING AND EVALUATION
}

\author{
Cary J. Peaden \\ NASA KSC Spaceport Processing Services Branch \\ Mail Stop: YA-D8 \\ Kennedy Space Center, FL 32899, U.S.A.
}

\begin{abstract}
This document describes some of the history and uses of simulation systems and processes for the training and evaluation of Launch Processing, Mission Control, and Mission Management teams. It documents some of the types of simulations that are used at Kennedy Space Center (KSC) today and that could be utilized (and possibly enhanced) for future launch vehicles. This article is intended to provide an initial baseline for further research into simulation for launch team training in the near future.
\end{abstract}

\section{INTRODUCTION}

When most people think of NASA Simulations, they think of Astronaut training simulations, or in-space visualization simulations such as demonstrating how some remote activity will take place in space, or simulations for trade-off-analysis of new processes and architectures in competing designs. These applications are valuable and interesting areas for NASA to apply simulation. However, one additional area that is just as important, but often under appreciated, is the use of simulations for the training and evaluation of Launch, Mission Control, and Mission Management teams. (A closely related area is using simulations for the checkout of the systems and processes that those teams use.)

\subsection{Launch Team Training and Evaluation is Important}

Simulation training of the Mission Management, Launch, and Mission Control teams is critical to the safety of space shuttle processing. Realistic simulations, evaluations, and feedback within a safe environment provide one of the best methods for ensuring that teams have the experience, knowledge, and capabilities required for correct action during critical operations.

Some very good high fidelity simulation training for Launch Team, Mission Control, and Mission Management does take place today, and the details in these simulations are improving, but further enhancements are always possible and should be sought. This paper discusses some of what NASA does today, in an attempt to describe a baseline of our current situation, with plans for future work and proposed enhancements in following papers.

\subsection{A Focus on Launch Team Training and Evaluation is Timely and Interesting}

After the Columbia accident, everyone at NASA was required to read The Columbia Accident Investigation Board's (CAIB) Report Volume I. The CAIB's "Chapter 6: Decision Making at NASA", makes clear the fact that NASA's team decision-making had some problems that needed to be corrected. CAIB Return to Flight (RTF) recommendation R6.3-1 (on pages 172 and 226) is very relevant to the topic of this paper. It states that NASA must "Implement an expanded training program in which the Mission Management Team faces potential crew and vehicle safety contingencies beyond launch and ascent. These contingencies should involve potential loss of shuttle or crew, contain numerous uncertainties and unknowns, and require the Mission Management Team to assemble and interact with support organizations across NASA/Contractor lines and in various locations." One of the references to this paper, "Space Shuttle Program Directive NO 150A -Training Plan for Mission Management Team (MMT) and Members", August 23, 2004, is NASA's response to this CAIB recommendation. (NASA has now implemented the plan and complied with this RTF requirement.)

The author received additional motivation for research into this topic when he attended briefings provided by NASA KSC developers of the Shuttle Ground Operations Simulator (SGOS). The briefings explained how SGOS was developed and how it is used for the checkout of the shuttle Launch Processing System (LPS) and the training of the shuttle launch team. The author also attended some shuttle launch team training sessions with the NASA KSC Simulation Team. The work done by these two teams is very important for NASA. NASA should consider expanding that type of work to improve its capabilities, especially as it develops new vehicles for new missions under the Exploration Program. 


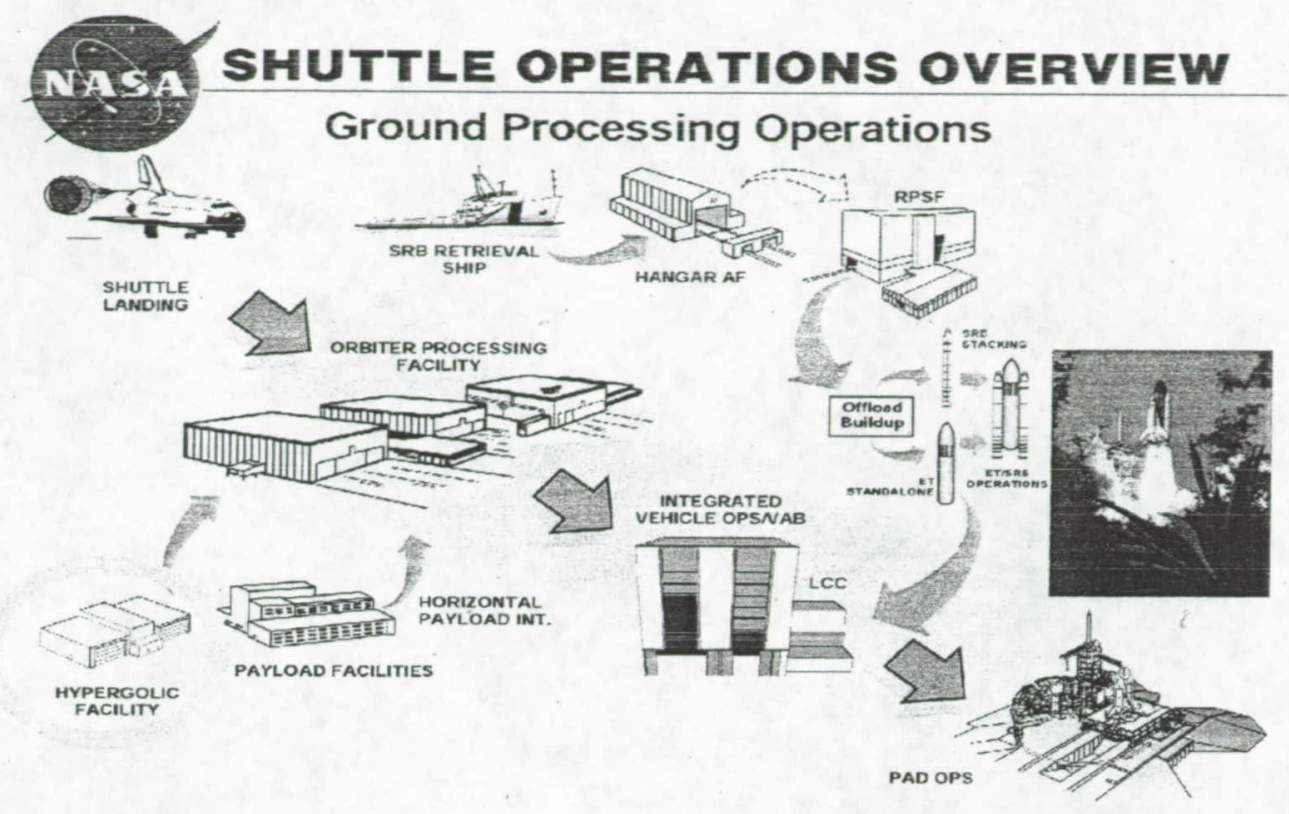

Figure 1 -Processing of Space Shuttles is a Complex Team Effort (from page 1 of a KSCSimEdge.ppt presentation provided by SGOS Developers)

\section{THE LAUNCH PROCESSING PROCESS}

Figure one shows that the ground processing of the space shuttle is a complex team effort. The figure focuses on ground processing from landing and delivery through assembly and launch. Today most of this activity is a responsibility of KSC.

Simulations can be very helpful in the modeling and optimizing of this type of spaceport processing activity, but that is not really the focus of this paper. This paper focuses on using simulation for the training and evaluation of the personnel who control and perform that ground and launch processing.

\section{THE PEOPLE}

The following sections describe some of the key personnel who are involved in launch team training.

\subsection{Personnel Who Require Simulation Training}

There are at least four categories of NASA Shuttle personnel who require simulation training: the Flight Crew, Mission Control, the Launch Processing Team, and the Mission Management Team.

\subsubsection{Flight Crew}

The flight crew is the best known and the most visible group involved in the shuttle program. A flight crew for a space shuttle ranges in size from two to eight. Its members pilot and care for the shuttle and its payload while in flight, and perform the on-orbit tasks required for the mission. When compared with total NASA time devoted to each mission, time on-orbit is extremely valuable and limited, so a well-trained flight crew is critical to a mission's safety and success.

\subsubsection{Mission Control}

NASA's Mission Control is located at Johnson Space Center (JSC), in Houston, Texas. While the orbiter is in flight, mission controllers sit on station at consoles in Flight Control Rooms (FCR), monitoring and controlling the space shuttle missions, communicating with the flight crew, and providing their on-orbit ground based support. Mission Control also has many support personnel that don't sit in the FCR, but who do provide valuable support and analysis to the mission controllers and flight crew. 


\subsubsection{Launch Processing Team}

Most of the focus of this paper is targeted at simulation for Launch Team Training. The Launch Team is composed of employees from NASA, the Space Flight Operations Contractor (SFOC), and other organizations. They are the people that perform most of the activities shown in figure one. They are primarily located at KSC. Figure two provides a hierarchical representation of the Space Shuttle Launch Team.

The KSC Shuttle Launch Team sits at consoles in the Launch Control Center's "Firing Rooms" (see figure three). They provide control and monitoring of critical activities that occur during shuttle ground processing, launch, and landing. KSC has two firing rooms (FR1 and FR3) that it uses for the Prime Launch Teams' operations. $\mathrm{KSC}$ also has one backup firing room (FR2) that it uses for additional support and training. Each firing room has twelve to fifteen consoles. During a launch, the prime fir- ing rooms are manned by console operators serving as the Primary System Engineers (PSE), System Specialist Engineers (SSEs) and other supporting systems specialist.

The operations are led by the NASA Test Director (NTD), and the Launch Director (LD), with engineering integration managed by the Shuttle Project Engineer (SPE). The backup firing room is manned by the Chief Engineer and Engineering Team Leads (ETL) and support teams. Other Firing Room support is provided by representatives from Johnson Space Center (JSC), the Eastern Range, Safety, and the Payloads communities.

In addition to the personnel in the firing rooms, there are also a great many support personnel and facilities across-KSC, the Space Shuttle Program (SSP), and NASA that participate in the processing and the launch of space shuttles (and who could also potentially benefit from some simulation training).

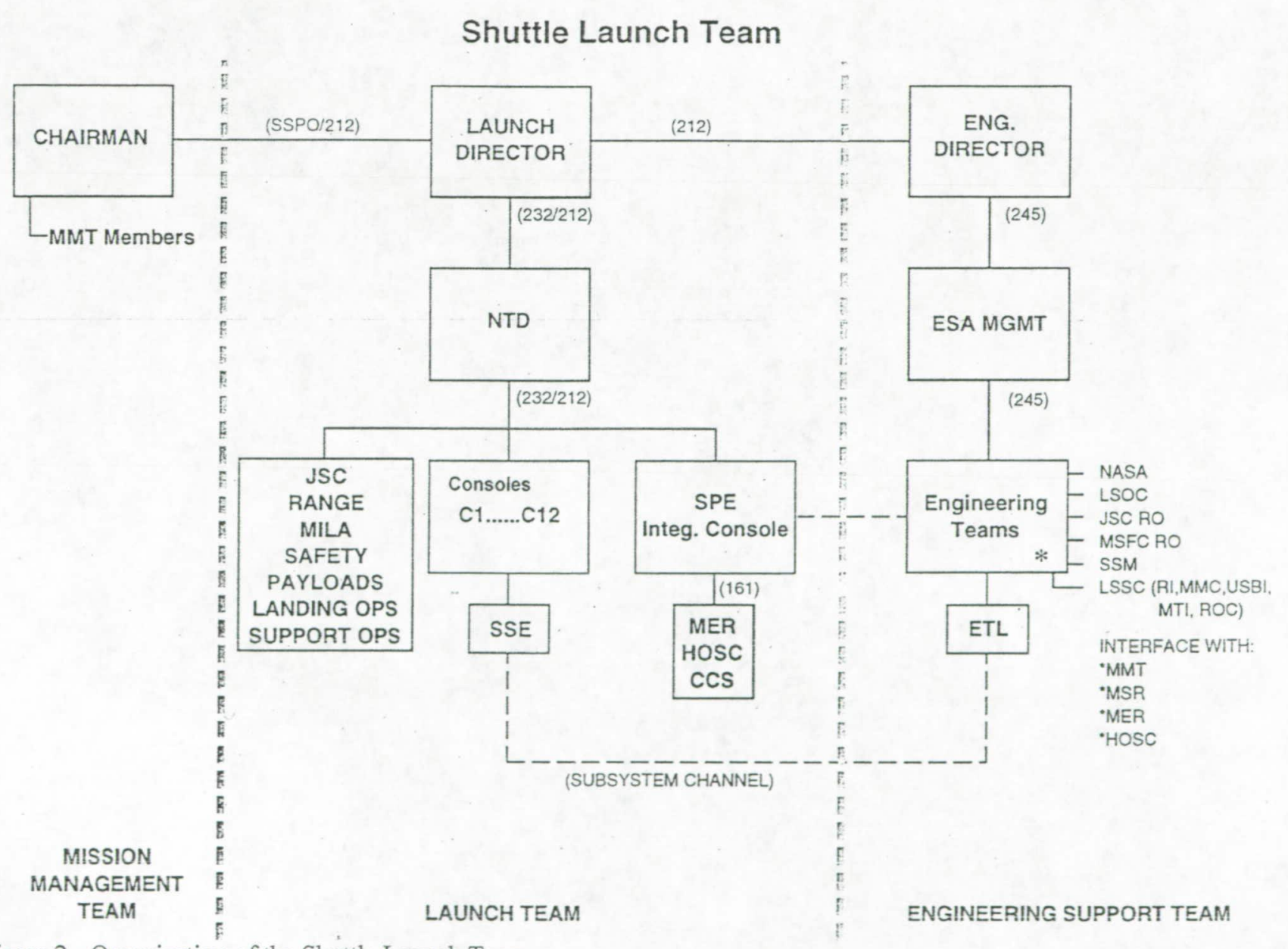

Figure 2 - Organization of the Shuttle Launch Team

(from the Space Shuttle Launch Team, June 8, 1995, <science.ksc.nasa.gov/shuttle/countdown/launch-team.html>) 


\subsubsection{Mission Management Team}

Overall responsibility for the space shuttle missions resides with the Mission Management Team (MMT), which is staffed by senior managers from across the Space Shuttle Program. The MMT is activated at the Pre-launch Mission Management Team (PMMT) review two days prior to the scheduled launch (i.e. L-2). The MMT is chaired by the Deputy Manager, Space Shuttle Program (SSP). At T-9 minutes, the Launch MMT is polled for a GO / NO GO launch decision and the Deputy SSP Manager makes the final planned GO / NO GO decision.

After a T-9 minute GO Decision the launch is automated via a Ground Launch Sequencer (GLS) program that runs the remainder of the countdown autonomously. The GLS can abort the launch based on its approximately 1,500 sensor inputs which monitor Launch Commit Criteria (LCC), or based on a command from a human, but if all LCC remain good, and no human intervenes, the Space Shuttle will be launched. At T-31 seconds, control of the launch switches from the GLS to internal computers within the Shuttle.

Once the Solid Rocket Boosters (SRBs) ignite, the control of the space shuttle switches from the firing rooms in the KSC Launch Control Center, to the Mission Control Rooms in the JSC Mission Control Center.

\subsection{KSC Personnel who Provide some of the Components for Simulation Training}

There are at least four categories of KSC personnel who provide some of the components required for simulation training: the NASA SGOS Developers, SFOC Math Modelers, SFOC Test Project Engineering, and the NASA Shuttle Simulation Team.

\subsubsection{NASA SGOS Development Team}

When the Space Shuttle Program started in the 1970s, KSC developed a Launch Processing System (LPS) for the Launch Processing Team to use. While developing LPS, KSC had to concurrently build a simulation system to check out the LPS and its application code. That simulation is now called the Shuttle Ground Operations Simulation (SGOS).

Both LPS and SGOS evolved and improved over the next thirty years. Some major improvements that have been carried out in the past ten years by a team of about ten NASA and contractor software developers include:

- The re-hosting of the SGOS software from a mainframe computer down to a single VME card while increasing the systems performance and capability by an order of magnitude.

- Replacing a video switching interface with a real-time simulation interface.

- Making the new SGOS compatible with other system interfaces (including the KATS and CITE systems - not discussed in this paper).

NASA SGOS Development Team members spent time explaining their architecture to the author, and he believes that NASA should consider employing some of their acquired expertise when developing any future Enhanced Ground Operations Simulation for the soon to be developed Exploration vehicles.

\subsubsection{SFOC Math Modelers}

SFOC provides Math Modelers, who develop simulations of the Space Shuttle and the Ground Support Equipment (GSE) using the SGOS Language. These math modelers work with system engineers and an understanding of physics and ground processing systems to develop simulations of the physical measurements monitored and the equipment and behaviors controlled using the LPS.

\subsubsection{SFOC Test Project Engineering}

The SFOC Test Project Engineering (TPE) organization is responsible for staffing the Integration console in support of the SPE for launch engineering integration and problem resolution for launch. It also rotates assignment of these same engineers to the development of large integrated (Tier 3) Team Training Simulations.

\subsubsection{NASA Shuttle Simulation Team}

In 1998, due to shortened launch window time constraints imposed by routine space station missions, NASA KSC decided to increase the simulation training frequency and depth beyond what the SFOC TPE was providing. So, NASA created a simulation team to improve KSC's simulation capabilities by providing lower tiered (detailed) training simulations, which will be described in more detail later.

This NASA simulation team is responsible for developing, scheduling, and running tiered training simulations. They use SGOS and the math models to create their simulations. Their challenges include deciding which sub-teams to train, where and how to introduce faults, and preplanning troubleshooting scripts that the simulations should take and against which they can evaluate performance. 


\subsection{Shuttle Launch Processing System (LPS)}

The Launch Processing System (LPS) is the primary system of computers used to process and launch space shuttles. LPS was developed at KSC in the 1970s, but has evolved in the thirty years since. It is composed of several major subsystems including the Checkout, Control, and Monitor Subsystem (CCMS), Central Data Subsystem (CDS), Record and Playback Subsystem (RPS), Front End Processors (FEPs), and Hardware Interface Modules (HIMs). The primary human interface to LPS is at the CCMS Consoles, where the SFOC and NASA Controllers sit, in the KSC firing rooms. Figure three shows engineers sitting at LPS CCMS Consoles in a firing room within the Launch Control Center at KSC. The end item interface for LPS is the HIMs. End items are the monitored or controlled items: the Space Shuttle and its Ground Support Equipment (GSE).

\subsection{Shuttle Ground Operations Simulator (SGOS)}

NASA and SFOC use the Shuttle Ground Operations Simulator (SGOS) for testing, validation, and verification of the LPS, the launch team, and their processes, to insure that they are prepared to control the and launch vehicle and GSE, and that they are prepared to launch.
SGOS allows the launch team trainers to introduce faults and abnormal situations into the simulated launch vehicle and GSE, and observe how the launch team handles the situations. It allows individuals and teams to identify, overcome, and learn from weaknesses in a safe environment without damaging the real vehicle and GSE or risking lives.

The SGOS system has evolved over the past thirty years, and its newer version are sometimes called the "KSC Simulation System", but it still runs the legacy math models written in the SGOS Language, so for this paper the term SGOS will be used. SGOS has two modes of operation: Real-Time mode (RT) and Interactive Remote Terminal mode (IRT). A Simulation Application Programming Interface (SimAPI) library has been developed for SGOS and it allows external control and monitoring of the math models. Figure four shows how LPS (the Real-time Processing System block) interfaces to the vehicle or the SGOS (the Simulation System block). Personnel operating the consoles in the firing rooms can't easily tell the difference from the data displayed on their consoles, because the simulation is high quality. One big difference between the two alternative configurations is that mistakes that happen while in simulation training are safe learning experiences while those made while controlling real equipment can potentially be catastrophic.

Figure five is a similar diagram where the blocks are represented by pictures of the actual items. The Real-time Universal Simulation System is a primary component of the SGOS System (on a VME card).

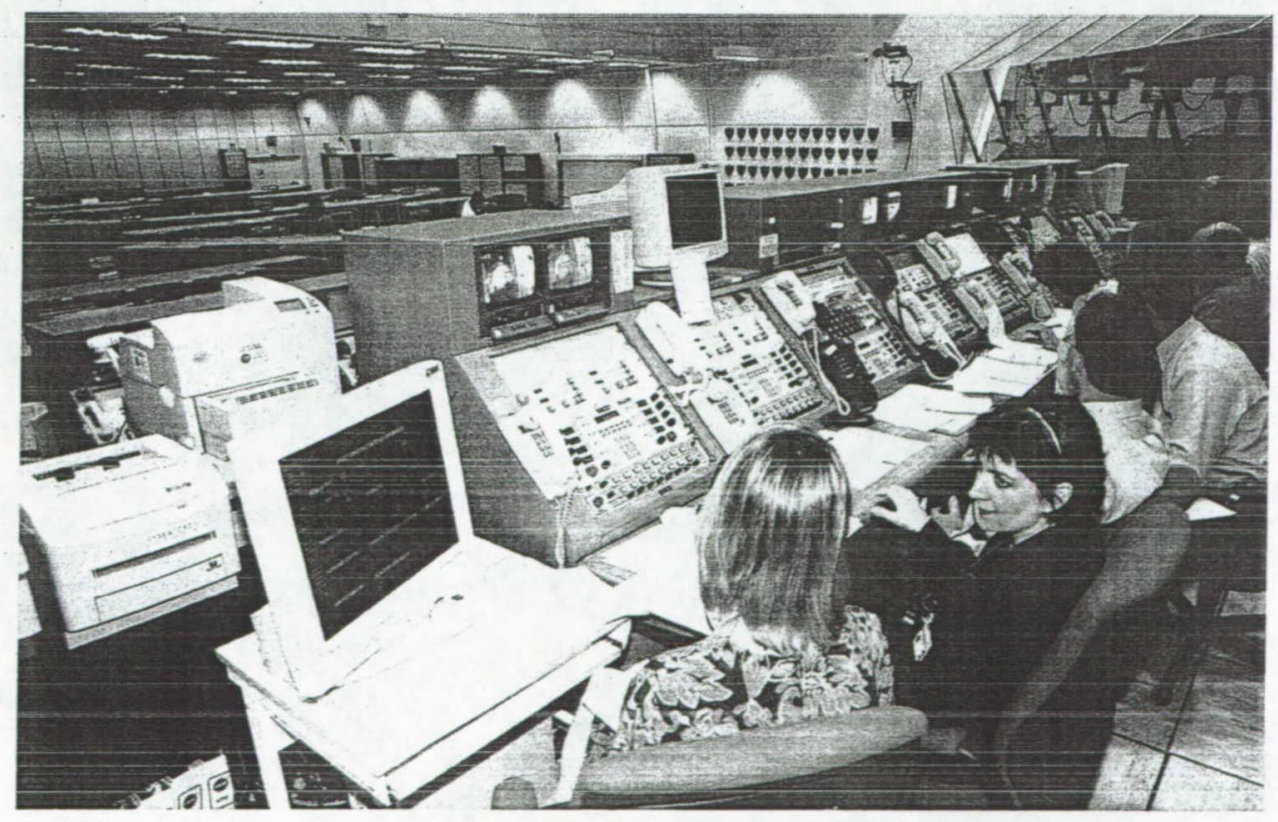

Figure 3 - KSC firing room during an Integrated Shuttle Launch Team Simulation (from KSC Photo Archive) 


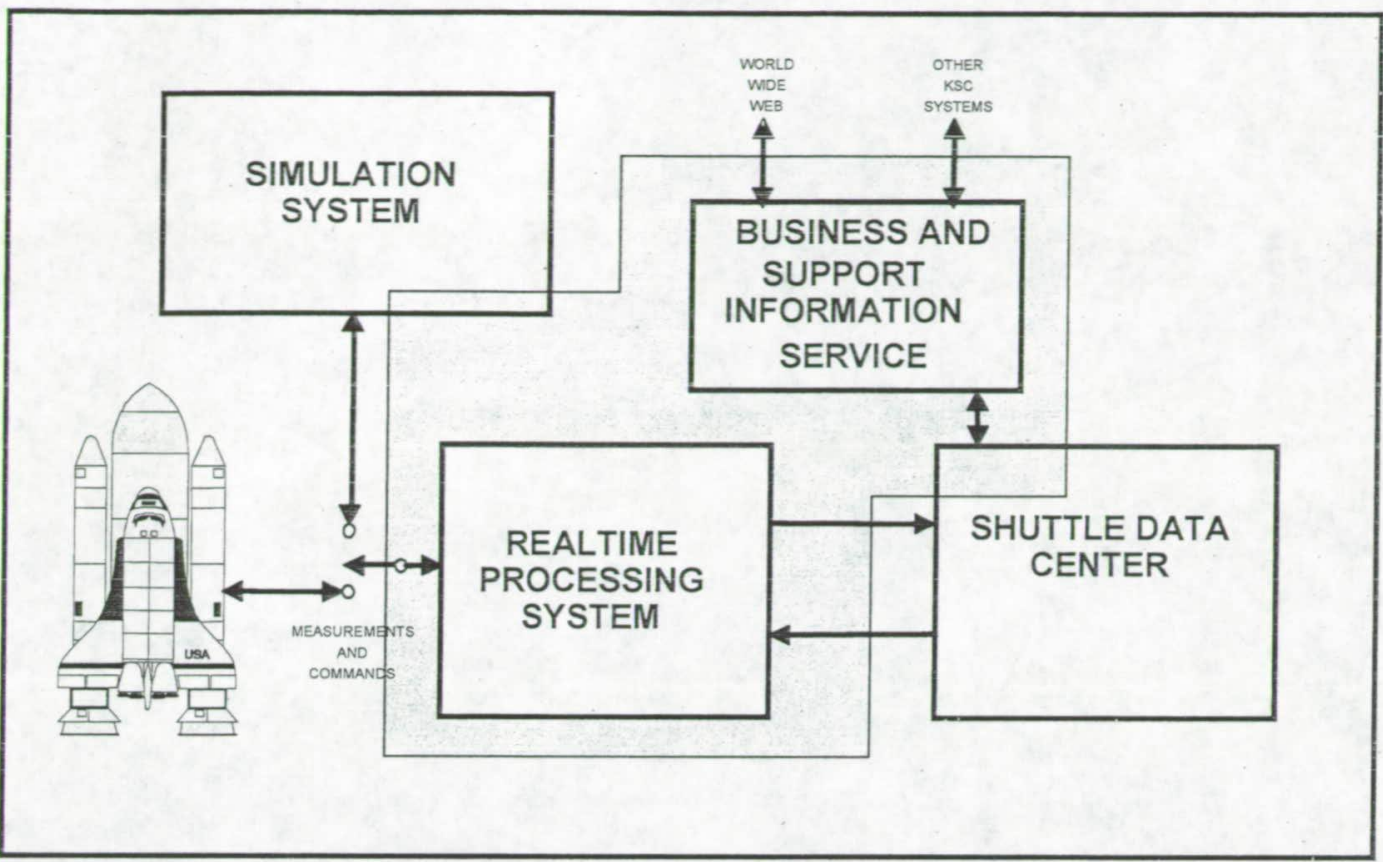

Figure 4 - Launch and Simulation System Architecture

(from page 2 of KSCSimEdge.ppt presentation provided by SGOS Developers)

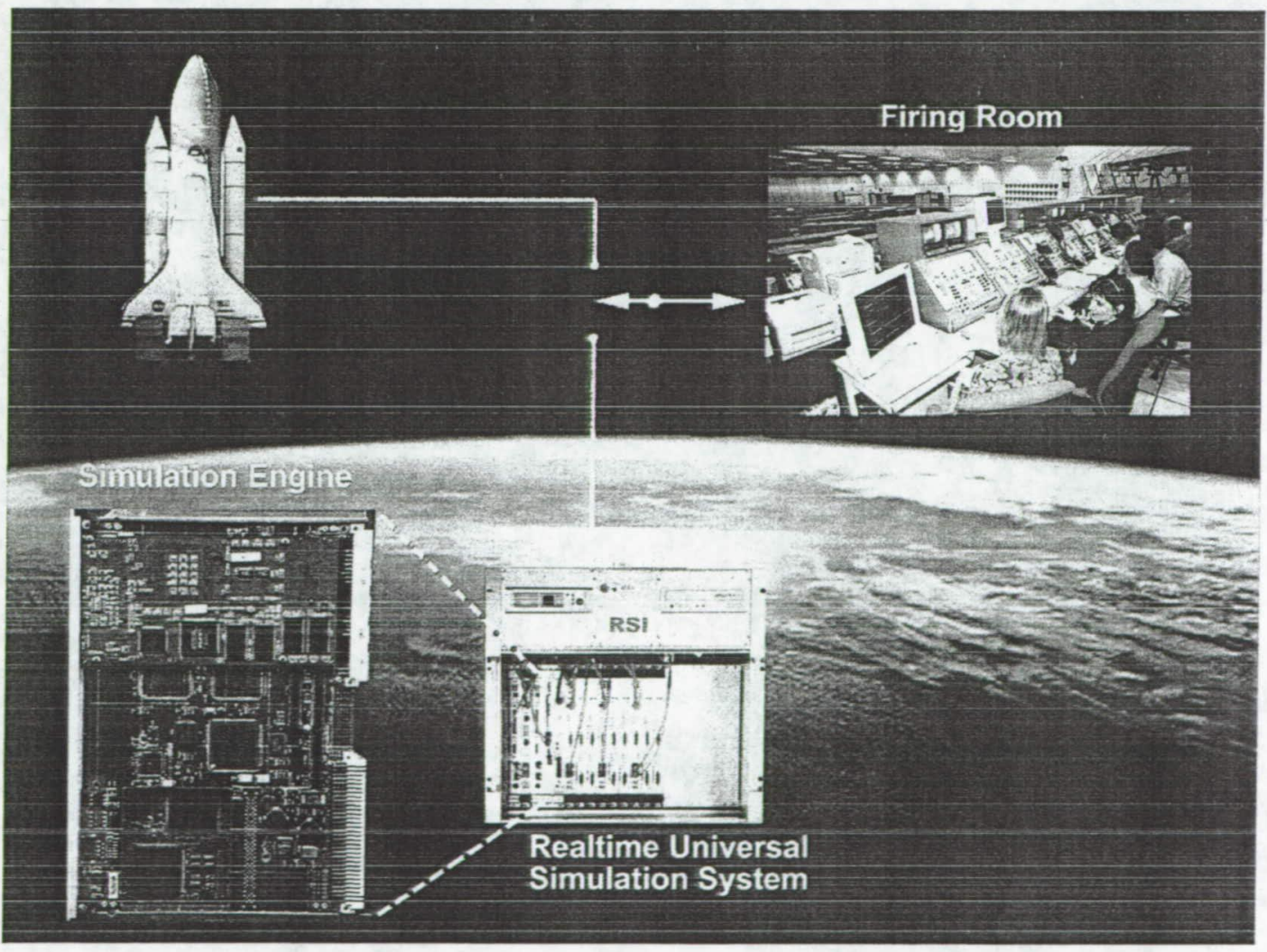

Figure 5 - Real-time Universal Simulation System simulates the Vehicle and GSE (modified from page 4 of KSCSimEdge.ppt presentation provided by SGOS Developers) 
One of the strengths of the recent SGOS development efforts is that the development team selected and used commodity and often free products and tools. During the evolution of SGOS, the math models had to remain in the SGOS Language to avoid loss of the large investment in legacy development and training efforts, but the underlying SGOS engine was rewritten in or ported to " $\mathrm{C}$ " code. The free tools used include gcc, gdb, and Tcl. The newest versions of SGOS are now very portable and could be very valuable for the simulation efforts of future launch vehicle and GSE. One ongoing NASA KSC project includes a soon to be completed work package that will port SGOS to run on a Linux laptop.

\section{TYPES OF TEAM SIMULATION TRAINING AND EVALUATION}

Several types of training and evaluation are relevant.

\subsection{Tiered Simulation Training of the Launch Team}

Tiered training at KSC is a little over five years old. Prior to 1998, KSC just ran large integrated simulations, which are now classified as Tier 3 simulations. Tighter launch windows imposed by space station missions reduced NASA's tolerance for errors. NASA and SFOC's solution to that decreased tolerance for errors included increasing the details in and frequency of simulation training at lower organizational levels.

Tier 3 Training Simulations are used to test out large integrated shuttle launch processing steps. The primary Tier 3 simulation is Operations and Maintenance Instruction (OMI) S0044 - shuttle final countdown simulation starting at T-20 minutes and running to launch. Tier 3 simulations are all day events that involve the complete launch team, and typically include the Flight Control Team at JSC and the Huntsville Operations Support Center at Marshall Space Flight Center. This level of training is very valuable, but it requires a large investment of everyone's time, and many individuals play only a very minor role. NASA and SFOC are typically only able to conduct this type of training once or twice prior to each launch. The author observed a Tier 3 S0044 training simulation on August 4, 2004.

Tier 2 training simulations are used to test out interactions and required troubleshooting across two or more partially integrated systems. One example of a Tier 2 training simulation is a power simulation that involves three systems: Electrical Power Distribution and Control (EPDC), Environmental Control and Life Support (ECLSS), and Fuel Cell Powerplant / Power Reactant Storage and Distribution (FCP/PRSD). This particular tier 2 simulation was created as a result of a weakness that was identified during a S0044 simulation. Other Tier 2 simulations include the OMI S0066 - simulated hypergolics loading of the Orbital Maneuvering System (OMS) Pods, and CryoSim - simulated shuttle tanking (liquid loading) from T-6 Hrs to T-3 Hrs. Usually Tier 2 simulations are half-day events, but occasionally they are full day exercises. Since these simulations involve fewer trainees, their involvement, challenges, and value to the average trainees are significantly increased. The quality of the training per trainee is higher, but the number of people trained per session is of course lower.

Tier 1 Training Simulations are used to test out individual systems and system engineers. For example, on July 29, 2004, the author observed a Tier 1 simulation that was developed for the Environmental Control and Life Support Systems (ECLSS) system and engineers. Tier 1 simulations usually take a half-day. Since these simulations are focused on a particular system and a small group of engineers, the thoroughness of the individual training for the average trainee can be significantly higher than either of the higher tier simulations. Of course there is great value in working with a large team, and those higher-level simulations provide that larger cross team value.

\subsection{Simulation Training for the Flight Crew and Mission Control}

From research it appears that the simulation training provided and required for the Flight Crew at JSC appears to be very thorough and of high quality. JSC's Mission Control is also known for a high level of training. The author hopes to JSC sometime during this upcoming year to learn specifics of how they use simulation for their training of the Flight Crew and Mission Controllers.

\subsection{Simulation Training for the Mission Management Team}

The Mission Management Team (MMT) appears to be one of the most important real time decision making bodies for the space shuttle, yet it seems to be historically one of the least well trained from a team perspective. A document that supports this theory is "Appendix D.1 STS-107 Training Investigation" of the Columbia Accident Investigation Board Report Volume II, U.S. Government Printing Office. Oct. 2003. It notes that only six MMT simulations were held prior to the Columbia accident.

If you read Chapter 6 - "Decision Making at NASA" of the CAIB Report Volume I Report, you will see that the MMT made several critical mistakes during the Columbia flight which contributed to the accident. From research into the Challenger accident, it is apparent that several high level mistakes were also made then, includ- 
ing the decision to waive the booster constraints on minimum launch temperatures.

Fortunately, it appears that NASA is addressing this problem. During the recent Return-to-Flight period, the MMT participated in numerous simulations with the launch processing team. An August 23, 2004, "Space Shuttle Program Directive NO 150A -Training Plan for. Mission Management Team (MMT) and Members" documents the current mandatory MMT training needs and certification requirements.

\subsection{Simulation Training for the NASA Expendable Launch Vehicle (ELV) Team}

NASA's Expendable Launch Vehicle (ELV) organization forms Rehearsal Anomaly Teams (RAT) to practice launch operations, but they don't have a simulation engine and math models like those provided by the SGOS system that actually plays the role of the Launch Vehicle and the Ground Support Equipment, and the ELV simulations are less elaborate than those used for shuttle.

That is probably fine for the role that NASA is currently playing in that unmanned space program. However, NASA is considering putting a manned capsule on top of one of the ELVs (or a shuttle derived vehicle) to meet some Exploration Program needs. If NASA decides to do that, the agency will obviously have to reexamine ELV testing and training programs for that new manned vehicle. Something like SGOS, perhaps an Enhanced Ground Operations Simulation (EGOS), will be one of the many new capabilities required. NASA should consider the requirement for launch system checkout and launch team training while developing next generation vehicles and launch processing system concepts and alternatives.

\section{SIMULATION RECOMMENDATIONS FOR FUTURE VEHICLES}

From readings and discussions with experts in the simulation and training fields, the following preliminary recommendations were identified:

- Learn from past experiences and the current baseline.

- Develop distributed tiered simulation capabilities

- Utilize standards.

- Develop and integrate simulations of the vehicle and the launch systems while you develop the vehicle and launch systems. Don't wait until the vehicle is developed to begin developing the simulation infrastructure.

- Prepare to certify the launch team for a whole new vehicle.

- Train NASA system engineers to the same or better standards as those used for the contractor's system engineers. (According to one of the NASA Sim Team members, there are certification training requirements for the SFOC system engineers, but training requirements for the NASA system engineers are less stringent.)

- Study how our military, other government organizations and industry are using simulations for training and evaluation of their workforce and consider applying some of their technologies and lessons learned in improving NASA's simulation training and evaluation.

- Recent reports indicate that NASA's Exploration vehicles may include shuttle derived components and therefore may benefit from the reuse of some elements of SGOS. Consider adding High Level Architecture (HLA) support to the SGOS Architecture so that it can communicate with other simulations using that DOD and IEEE simulation interface standard.

- Consider whether it might be possible and beneficial to add some low fidelity software simulated humans to certain training curriculums. Today NASA KSC simulates the vehicle and ground support equipment using software (SGOS), but NASA KSC doesn't simulate the humans with software. Research into simulated humans might eventually allow us to provide ondemand simulations of absent teammates and improve the availability of some training while reducing costs.

\section{FINAL THOUGHTS}

Because of budget, resource, and time constraints, NASA must prioritize. With respect to training and evaluation simulations, NASA's historical priorities seem to have been the Flight Crew, Mission Control, Launch Control, the Mission Management Team, and then the supporting ground based team. It appears that NASA may not have given enough attention to all of the priorities. Increasing resources spent in the lower priority training areas is prudent.

In the future, simulation is going to become even more important to NASA, and to our country, if we want to operate safely and remain competitive with other space programs. NASA must continue to invest in these applied types of simulation technologies and training sessions and to research related new technologies. NASA needs to build from what it has learned. The author has confidence that NASA will. 


\section{Kuhl and Steiger}

\section{ACKNOWLEDGMENTS}

The author wishes to thank:

- The NASA Space Shuttle Simulation Team including Jeff Campbell, John Apfelbaum, and Stephen Colubiale for allowing him to sit in on several launch countdown simulations, and explaining how they plan for and use SGOS to conduct training sessions for the Shuttle Launch Team, and for making recommendations for future launch teams.

- The developers of SGOS including Chuck Lostroscio, Nathan Taylor, and Scott Estes who explained the SGOS system, and made recommendations for improvements in future simulation systems.

- Peter Nickolinko from the KSC NASA Test Directors Office who provided some important corrections to draft versions of this paper.

- His UCF PhD Advisor: Dr. Avelino Gonzalez, who through courses and in brainstorming sessions has helped spark his interest in this area.

- His past and present managers and his sponsor: Tommy Mack, Erik Denson, and Faith Chandler, who have been supportive of his desire to perform research in this area.

- The NASA and contractor teams, with whom he is proud to work.

\section{REFERENCES}

"Appendix D.1: STS-107 Training Investigation". Columbia Accident Investigation Board Report Volume II. U.S. Government Printing Office. Oct. 2003.

Banke, Jim. "NASA's Revamped Mission Management Team Prepares for the Future". Space.Com. Feb 11, 2004. Available via

<www.space.com/missionlaunches/mmt hale_040211.html> [accessed February 4, 2005].

"Chapter 6: Decision Making at NASA". Columbia Accident Investigation Board Report Volume I. U.S. Government Printing Office. Aug. 2003.

"Interview of Jeff Campbell". NASA/Kennedy Space Center Multimedia Gallery. Apr. 1, 2004.

Available via

<www. mediaar-

chive.ksc.nasa.gov/detail. cfm?media

id $=22318>$ [accessed February 4, 2005].

"Interview with Jeff Campbell and Observation of Tier 1A Simulation for ECLSS". Jul. 29, 2004.

"Interview with John Apfelbaum and Observation of Tier 3 Simulation Training". Aug. 4, 2004.
"Interview with John Apfelbaum and Steve Colubiale". September 16, 2004.

"KSC Launch Team Certification Plan United Space Alliance Space Flight Operations Contract SFOCGO0008 Revision C DRD 1.5.2.3". May 15, 2001. Available via

$<$ usa-

houw7/rsbin/RightSite.dll/getconten t/Tempfile?DMW_DOCBASE=EDMSP\&DMW OB JECTID $=0900392 \overline{\mathrm{b}} 801 \mathrm{aed} 9 \mathrm{C} \& D M W$ FORMĀT $=$ pdf $>$ [accessed February 4, 2005].

"The KSC Simulation System". NASA Tech Briefs. Sept. 2, 2003. Available via <WWW. nasatech. com/Briefs/Dec00/KSC1 2121.html> [accessed February 4, 2005].

"The KSC Simulation System". NASA Tech Briefs, KSC -12121 . Available via <ww. nasatech.com/Briefs/Dec00/KSC1 2121.html> [accessed February 4, 2005].

"The KSC Simulation System - Technical Support Package. Shuttle Operations Overview." NASA Tech Briefs KSC-12121. Available via <www. nasatech.com/Briefs/Dec00/KSC1 2121. html> [accessed February 4, 2005].

"The KSC Simulation Team practices for contingencies in Firing Room 1". Kennedy Space Center Photo Archive. Aug. 20, 1998. Available via < images.ksc.nasa.gov/cgi-bin/findimage?ksc-98pc-0971\&html > [accessed February 4, 2005].

"Launch Control Center". NSTS 1988 News Reference Manual. Sept. 9, 2004. Available via <science.ksc.nasa.gov/shuttle/technolog y/sts-newsref/sts-lcc.html> [accessed February 4, 2005].

Peaden, Cary J. "Command, Control, and Monitoring Systems Development Efforts". Spring 2001.

Saucedo, Luis. "Launch Team Training Benchmarking". Jan. 10, 2003.

"Shuttle Ground Operations Simulation (SGOS)" presentation. KSCSimEdge.ppt slides. Provided by Scott Estes and Chuck Lostroscio. Sept. 11, 2003.

The Space Shuttle Launch Team. June 8, 1995. Available via <science.ksc.nasa.gov/shuttle/countdown / launch-team.html> [accessed February 4, 2005].

"Space Shuttle Program Definition and Requirements Program Structures and Responsibilities Book 2 Space Shuttle Program Directives - NSTS 07700, Volume VII BK2 Revision D”. Aug. 15, 1996.

Available via <sspweb.jsc.nasa.gov/webdata/pdcweb 
/sspdocs/NSTS07700 VolumeII Book2.p df $>$ [accessed February 4, 2005].

"Space Shuttle Program Definition and Requirements Operations - NSTS 07700, Volume VIII Revision E". Feb. 24, 1999. Available via <sspweb.jsc.nasa.gov/webdata/pdcweb/sspdocs/NST S07700_VolumeVIII.pdf $>$.[accessed February 4, 2005].

"Space Shuttle Program Directive NO 150A -Training Plan for Mission Management Team (MMT) and Members", August 23, 2004. Available via <sspweb.jsc.nasa.gov/webdata/pdcweb /sspdocs/NSTS07700 VolumeII Book2.p df $>$ [accessed February 4, 2005].

Tomayko, James E. "Chapter Seven - The Evolution of Automated Launch Processing" and "Chapter Nine Making New Reality: Computers in Simulations and Image Processing". Computers in Spaceflight: The NASA Experience. Contract NASW-3714. Mar. 1988. Available via <http://www.hq.nasa.gov/office/pao/ History/computers/Compspace.html> [accessed February 4, 2005].

Tomayko, James E. "Computers in Spaceflight The NASA Experience". NASA Contractor Report 182505. Wichita State University, Wichita Kansas. Sept. 9, 2004. Available via. http://www.hq.nasa.gov/office/pao/H istory/computers/Compspace.html [accessed February 4, 2005].

Wells, Joel. "Practice Makes Perfect for KSC Launch Team". KSC Release No. 94-98. Aug. 19, 1998. Available via <wwwpao.ksc.nasa.gov/kscpao/release /1998/94-98.htm > [accessed February 4, 2005].

\section{AUTHOR BIOGRAPHY}

CARY J. PEADEN is a member of NASA KSC's Spaceport Engineering Technology Directorate. He has over 18 years of experience with NASA. During his career he has served as a software engineer, communications engineer, systems engineer, project manager, technical team lead, and as the Chief of a Software Engineering Branch. He recently served as the Project Manager and Contracting Officer's Technical Representative for NASA's Next Generation Launch Technology Program's Advanced Checkout, Control and Monitoring System (ACCMS) project and the Intelligent Systems Program's Virtual Testbed (VTB) for Range and Spaceport Operations Simulation project, and as the Project Manager for the Exploration Program's Supply Chain Simulation project. $\mathrm{He}$ is now working as the Principle Investigator on an Office of Space Flight and Mission Assurance Program's Human Behavior Modeling and Simulation for Launch Team Training and Evaluation study. He holds a B.S.E. in Electrical Engineering, an M.S. in Computer Science, an M.S. in Engineering Management, and is pursuing a Ph.D. in Computer Engineering. He is registered as a Professional Engineer with the state of Florida. His email address is <cary.j.peaderienasa.gov>. 